\title{
Political economy of covid-19: extractive, regressive, competitive
}

\author{
The political economy of covid-19 reflects longstanding patterns of resource extraction linked to \\ racial discrimination, marginalisation, and colonialism, write Jesse Bump and colleagues
}

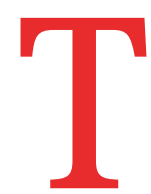

he common challenge of covid19 has produced very different outcomes around the world, leading to many questions about the determinants of national performance and shortcomings in global performance. Problems of reporting and standards do not make precise comparisons easy, but few would disagree that the roughly 1400 deaths reported by South Korea, Thailand, and Vietnam together represent far better results than the roughly 700000 deaths reported by Brazil, the United Kingdom, and the United States. ${ }^{1}$ Adjusting these figures for population-the first group has about a third of the citizens of the second group-does not explain why covid-19 mortality differs by a factor of nearly 500. Neither typical proxy measures such as gross national income per capita nor national rankings on the 2019 Global Health Security Index have any meaningful association with performance on covid-19. ${ }^{2}$

The seeming uncertainty in the determinants of national achievement contrasts with the familiar pattern of subnational outcomes in places where covid-19 has taken hold: morbidity and mortality are far worse for indigenous people, migrants, black people, and other victims of racism, discrimination, and

\section{KEY MESSAGES}

- Countries have had very different experiences with covid-19, raising questions about its political economy and the determinants of performance

- The burden of covid-19 follows extraction patterns dating from colonial times, with the worst outcomes suffered by marginalised people and poorer countries

- Competitive attitudes by some countries have undermined the international response

- Progress in public health requires governance reforms at multilateral institutions and international redistribution mechanisms marginalisation. ${ }^{3-6}$ This pattern reflects underlying inequality in opportunity, education, wealth, and access to care, and in physical distancing policies that have forced people to rely on their own resources. The risks of economic disruption and disease transmission have disproportionately affected people in lower paid service sector jobs, where many already marginalised citizens find their employment. Domestically, the toll of covid-19 has been regressive, meaning that poor and marginalised people have suffered disproportionately more than rich people. Internationally, many countries have adopted a competitive attitude, competing against others for access to supplies or commercial advantage in pharmaceuticals. ${ }^{7}$ This nationalistic competition is contrary to global interest and is likely to harm countries and citizens of the global south. ${ }^{7}$ The countries most likely to be deprived of vaccines, medicines, and supplies are those with the least economic and political bargaining power.

\section{Colonialism and the political economy of extraction}

To examine these patterns of covid-19 more closely is to ask about the political economy of the disease, which refers to the distribution of the effects of covid-19, the behaviour of nations, and the power relationships that these factors reflect. Overall, we interpret the broad patterns in the regressive distribution of disease and the competitive scramble for vaccines and supplies to indicate that the political economy of covid-19 is the political economy of extraction, following longstanding patterns of exploitation. Extractive relationships are fundamentally unequal and are the opposite of the collaborative fairness embodied in the general ideals and ethics of public health and in the specific calls for solidarity and cooperation made by the World Health Organization and nearly every country in a lengthy resolution at the 2020 World Health Assembly. ${ }^{8}$ Where collaborative relationships are based on shared values, common benefits, and equitable progress, extrac- tion is oriented around benefits for elite groups at the expense of others, divides society into the haves and have nots, and is defined by permanent inequity. Yet in many countries, the unequal toll of covid19 has exposed extractive domestic economic structures that disproportionately disadvantage the same racial and ethnic groups that were exploited under slavery or colonialism, and revealed inadequacies in social safety nets. Covid-19 has provoked competitive, individualistic foreign policies as well. These attitudes are in opposition to public statements of solidarity and the advocacy of civil society groups and United Nation agencies for an affordable and universally available vaccine. ${ }^{9-11}$

Internationally, the political economy of covid-19 reflects global patterns of extraction that were established in colonial times, some of which have continued since colonised countries became independent, including some embodied in medicine and public health. These patterns have important consequences in three areas: they undermine solidarity, increase economic inequalities, and amplify other vulnerabilities. Colonialism was built on extraction and based on ideas of cultural superiority that made solidarity unthinkable for dominant countries. ${ }^{12} 13$ These processes of colonialism and extraction and their effects explain much about the inequitable political economy of covid-19 and point to some possible remedies.

\section{Low solidarity}

The so called global health model presumes a north to south diffusion of ideas and resources "based in large part on technical assistance and capacity building by the US, the UK, and other rich countries."14 The arrival of covid-19 suddenly made many of these countries with a strong presence in global health focus on their own domestic vulnerabilities. This domestic focus revealed another persistent colonial attitude: poor countries exist to serve rich ones. In an April 2020 French television discussion, one physician suggested that 
clinical trials should be conducted in Africa "where there are no masks, no treatments, no resuscitation.” This exploitative attitude was explained with reference to past HIV trials carried out in commercial sex workers "because we know that they are highly exposed and that they do not protect themselves." ${ }^{15}$ Although few in global health would agree with these attitudes, the emphasis of the health sector on diseases and biomedical factors is a continuation of the colonial preference to overlook its own extractive economic policies and negative effect on the environment and other social determinants of health. ${ }^{16}$ By contrast, many countries in the global south have public health containment strategies developed through considerable experience with epidemic diseases including HIV infection, Ebola virus disease, Rift valley fever, and severe acute respiratory disease. Some African countries are pursuing inexpensive, effective strategies such as using community health workers for covid-19 track and trace. ${ }^{17}$ However, in keeping with the old colonial pattern of the flow of knowledge from north to south, these ideas and strategies have struggled to gain visibility in mainstream global health discussions. ${ }^{18}$

\section{Economic inequalities}

The global economic disruption caused by covid-19 has harmed poorer people and poorer countries the most, particularly in Africa, pushing an estimated 100 million people into extreme poverty in 2020 and reversing more than two decades of progress. ${ }^{19}$ Famines again threaten to affect countries across Africa and the Middle East as the virus destroys lives and livelihoods. ${ }^{20-22}$ The World Food Programme estimates that the pandemic will force as many as 272 million people into acute food insecurity. ${ }^{23}$ Avoiding additional damage to the economies of the global south will be possible only if new diagnostic tests, drugs, oxygen, and vaccines are made available in an equitable way. Many countries are collaborating to find solutions: Brazil, South Africa, and Egypt are among the 40 countries where vaccine trials are taking place. However, none of these countries has guarantees that they will receive a vaccine in any quantities, even though the trials are proving successful. The Covax facility ${ }^{24}$ includes an advanced market commitment under which rich countries pay in first to help provide vaccines to low and middle income countries. However, the exact financial relationships that convert these resources into a subsidy for pharmaceutical industry research are unclear and thus far have not included any details on ownership of intellectual property rights for any successful vaccines. Long term extractive relationships underpin these inequalities, including the capacity to negotiate payment ahead of time for vaccines. For example, Canada could afford to reduce the risk that some vaccines may not be proved efficacious and the risk of production delays by ordering five times more vaccine doses than it needed. On the other hand, nearly all low and middle income countries have been forced to wait in line to see what they can negotiate later, and wait for Covax to cover one fifth of the needed doses as it has pledged..$^{25}$ These are typical colonial relationships in which the resources of low and middle income countries are exploited by international private industry while their citizens remain dependent on the charity of rich countries.

\section{Increased vulnerabilities}

Colonial patterns increase vulnerability to covid-19 as well. Since the early 1900s, colonial industries such a mining have been linked to silicosis, tuberculosis, and other respiratory problems that increase vulnerability to covid-19. ${ }^{26-28}$ Similarly, sugar production has been a historic mechanism for extracting wealth from the communities that produce it, ${ }^{29}$ and products made from it, such as sugary drinks, alcohol, and many ultraprocessed foods, are risk factors for the exact comorbidities that contribute to worse covid-19 outcomes. About half of all covid-19 deaths recorded globally have occurred in patients with diabetes and hypertension and increasingly these products are sold in sub-Saharan Africa, Latin America, and India, creating new threats to health. ${ }^{30}$ Some companies making these products are using the pandemic to build their brands using strategic corporate social responsibility by providing "essential support" in the form of meals and hospital equipment, especially in the global south where resources are scarce. ${ }^{31}$

\section{Road ahead}

The longstanding patterns of extraction, the resulting vulnerabilities, and the specific problems presented by covid-19 all point to the need for change. In nearly all instances, these are changes that governments have committed to in the past but have not actually pursued. For example, countries committed to achieving universal health coverage (UHC) for their population at the 2019 United Nations General Assembly. Domestic inequalities are made worse by the current absence of UHC in many settings, which also impedes pandemic response since people excluded from healthcare because of cost and other barriers cannot seek care or self isolate when infected. Governments should prioritise pooled resources to provide full population coverage of a comprehensive package of health services, including vital public health services needed to prevent pandemics and basic primary healthcare needed to maintain wellbeing. Such coverage can be achieved only through progressive public financing. To be fair and effective, UHC must include marginalised groups, such as migrants, refugees, indigenous people, and people working in the informal sector. For those who have suffered most from extraction, including indigenous people, solutions must include enfranchisement with settlement of land rights and the provision of culturally appropriate services. ${ }^{32}$

Internationally, colonial patterns persist in many complex ways, although their consequences in systematically disadvantaging formerly colonised people and places is clear. The Commission on the Social Determinants of Health concluded in 2008 that health equity could not be achieved without dramatic redistribution of power and resources. ${ }^{33}$ The geopolitics of the covid-19 pandemic have shown that much work remains to be done in this respect. In the past three decades our world has grown more unequal, ${ }^{34}$ multinational corporations have flourished in a very deregulated global economy, ${ }^{35}$ and even as millions suffer and die now, many very rich people have become even more wealthy during the pandemic. ${ }^{36}$ Over the past few decades the planet's natural resourcesnecessary to sustain all life-have been depleted to dangerous levels, threatening human and planetary health alike. ${ }^{37}$ The common thread in these problems is the need for governance reform. Helpfully, the mechanisms that could be used to regulate the practices of transnational corporations have been described ${ }^{38}$ : these include reporting, reviewing, monitoring, and managing conflicts of interest; stopping the revolving door between transnational corporations and governments; protecting whistleblowers; and restricting and requiring full disclosure of lobbying activities. Similarly, the Transnational Institute has proposed binding treaties to regulate transnational corporations. ${ }^{39}$

Governance reform at the multilateral institutions would help advance the participation and power of low and middle income countries, including those formerly colonised. This reform would diversify 
the ideas and knowledge available for consideration and enable learning from the best examples, such as how African countries created a common marketplace to share access to scarce supplies at fair, fixed prices. ${ }^{40}$ Or how Senegal engaged communities to increase communication, case detection, and coordination for physical distancing and other policies. ${ }^{41}$ Traditional donor activities, which have included support of the African Centres for Disease Control, can still play a role, but more equitable governance of international institutions is a prerequisite for improving the global response to pandemics. Making international decision making democratic could support international collective action to empower WHO and assert the priority of health over commercial interests in international trade, and the joint pursuit of vaccines and other health technologies coupled with equitable distribution schemes. Some encouraging signs have emerged of progress towards these goals such as the ACT-Accelerator and the Covax facility, but the behaviour of some national governments (notably the US and UK) and powerful pharmaceutical groups is not fully supportive. ${ }^{42-44}$ Most crucially, these competitive actions in relation to vaccines are just one example of how unequal political and economic power linked to colonisation create health inequities between nations. These health differences will be solved only with far reaching reform of global economic and political systems. In our view, making governance of multilateral institutions democratic would be a good first step to reform, including equalising the opportunity to serve on the UN Security Council, the Executive Board of WHO, and the other decision making bodies of the international governance system. As a step towards economic redistribution, G7 and G20 countries should cross subsidise vaccine purchases for low and middle income countries and ensure long term availability by enforcing compulsory licensing as they have already pledged to do through the World Trade Organization. The shared disaster of the covid-19 pandemic has drawn attention to the many regressive realities of our world, each one calling for immediate reform in the governance of global health. Without such measures, the unfair, extractive, and regressive patterns of the past will continue to plague the present.

We thank Emily Coles for her help. JBB acknowledges non-specific support from the Bergen Centre for Ethics and Priority Setting, Bergen, Norway.
Contributors and sources: JBB has expertise in colonial and postcolonial history and has published widely on global health policy and international institutions in health. FB has published extensively on the socioeconomic determinants of health. MS has analysed the political economy of global health and has experience in international global health policy making. RY has long experience in global health policy and special expertise in the political economy of universal health coverage. $\mathrm{KH}$ has published extensively on the commercial determinants of health and the political economy of public health policy. The article was conceived jointly by JBB, FB, MS, RY, and $\mathrm{KH}$. JBB wrote the initial draft using inputs from $\mathrm{FB}$, $M S, R Y$, and $\mathrm{KH}$. All five authors revised and edited the article to produce a final draft. JBB is the guarantor.

Competing interests: We have read and understood BMJ policy on declaration of interests and have no relevant interests to declare.

Provenance and peer review: Commissioned; externally peer reviewed.

This article is part of a collection launched at the Prince Mahidol Awards Conference (PMAC) in January 2021. Funding for the articles, including open access fees, was provided by PMAC. The BMJ commissioned, peer reviewed, edited, and made the decision to publish these articles. David Harper and an expert panel that included PMAC advised on commissioning for the collection. Rachael Hinton and Kamran Abbasi were the lead editors for The BMJ.

Jesse B Bump, executive director ${ }^{1}$

Fran Baum, professor ${ }^{2}$

Milin Sakornsin, senior international relations officer $^{3}$

Robert Yates, senior fellow ${ }^{4}$

Karen Hofman, professor ${ }^{5}$

${ }^{1}$ Takemi Program in International Health, Harvard TH Chan School of Public Health, Boston, Massachusetts, USA

${ }^{2}$ Southgate Institute for Health, Society and Equity and WHO Collaborating Centre on the Social Political and Commercial Determinants of Health Equity, Flinders University, Adelaide, Australia

${ }^{3}$ Partnership and International Relations Section, Thai Health Promotion Foundation, Bangkok, Thailand

${ }^{4}$ Chatham House, London, UK

${ }^{5}$ SAMRC Centre for Health Economics and Decision Science, PRICELESS SA University of Witwatersrand Faculty of Health Sciences, School of Public Health, Johannesburg, South Africa

Correspondence to: J B Bump

bump@hsph.harvard.edu

\section{Check for updates}

This is an Open Access article distributed in accordance with the Creative Commons Attribution Non Commercial (CC BY-NC 4.0) license, which permits others to distribute, remix, adapt, build upon this work non-commercially, and license their derivative works on different terms, provided the original work is properly cited and the use is non-commercial. See: http://creativecommons.org/ licenses/by-nc/4.0/.

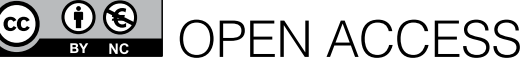

1 Coronavirus Resource Center. COVID-19 Dashboard by the Center for Systems Science and Engineering at Johns Hopkins University. Johns Hopkins, 2021. https://coronavirus.jhu.edu/map.html
2 Aitken T, Chin KL, Liew D, Ofori-Asenso R. Rethinking pandemic preparation: Global Health Security Index (GHSI) is predictive of COVID-19 burden, but in the opposite direction. J Infect 2020;81:318-56 doi:10.1016/j.jinf.2020.05.001

3 Dyer 0. Covid-19: black people and other minorities are hardest hit in US. BMJ 2020;369:m1483. doi:10.1136/bmj.m1483

4 Kirby T. Evidence mounts on the disproportionate effect of COVID-19 on ethnic minorities. Lancet Respir Med 2020;8:547-8. doi:10.1016/S22132600(20)30228-9

5 Bhala N, Curry G, Martineau AR, Agyemang C, Bhopal R. Sharpening the global focus on ethnicity and race in the time of COVID-19. Lancet 2020;395:1673-6. doi:10.1016/S0140-6736(20)31102-8

6 Baqui P, Bica I, Marra V, Ercole A, van der Schaar M. Ethnic and regional variations in hospital mortality from COVID-19 in Brazil: a crosssectional observational study. Lancet Glob Health 2020;8:e1018-26. doi:10.1016/S2214109X(20)30285-0

7 Santos Rutschman A. The covid-19 vaccine race: intellectual property, collaboration (s), nationalism and misinformation. Wash Univ J Law Policy 2020;64.

8 Seventy-third World Health Assembly. COVID-19 response. World Health Organization, 2020. https:// apps.who.int/gb/ebwha/pdf_files/WHA73/A73_R1en.pdf

9 Oxfam. What's a people's vaccine, and how can we get one? Oxfam, 2020. https://www.oxfamamerica. org/explore/stories/whats-a-peoples-vaccine-andhow-can-we-get-one/

10 Clark H, Byanyima W. The world needs a 'people's vaccine' for coronavirus, not a big-pharma monopoly. Guardian 2020 Jul 23. https://www.theguardian. $\mathrm{com} /$ commentisfree/2020/jul/23/world-needscoronavirus-vaccine-big-pharma-monopolyastrazeneca-patent-pandemic

11 Lynch C. 'America First' vs. 'The People’s Vaccine' Foreign Policy 2020 Jul 6. https://foreignpolicy. com/2020/07/06/coronavirus-vaccine-nationalismamerica-first-covax/

12 Slavin DH. Colonial cinema and imperial France, 1919-1939: white blind spots, male fantasies, settle myths. JHU Press, 2001.

13 Welch AR. Aboriginal education as internal colonialism: the schooling of an indigenous minority in Australia. Comp Educ 1988;24:203-15 doi:10.1080/0305006880240205

14 Dalglish SL. COVID-19 gives the lie to global health expertise. Lancet 2020;395:1189. doi:10.1016/ S0140-6736(20)30739-X

15 Check A. Yes, two French doctors said COVID-19 vaccine trial should be done in Africa. Africa check 2020 Apr 8. https://africacheck.org/fbcheck/ yes-two-french-doctors-said-covid-19-vaccine-trialshould-be-done-in-africa

16 Holst J. Global Health - emergence, hegemonic trends and biomedical reductionism. Global Health 2020;16:42. doi:10.1186/s12992-02000573-4

17 Ballard M, Bancroft E, Nesbit J, et al. Prioritising the role of community health workers in the COVID-19 response. BMJ Glob Health 2020;5:e002550. doi:10.1136/bmjgh-2020-002550

18 Hirsch A. Why are Africa's coronavirus successes being overlooked? Guardian 2020 May 21. https:// www.theguardian.com/commentisfree/2020/ may/21/africa-coronavirus-successes-innovationeurope-us

19 Reversals of fortune. International Bank for Reconstruction and Development, World Bank, 2020. https://openknowledge.worldbank.org/bitstream/ handle/10986/34496/9781464816024.pdf

20 Gladstone R. First famines of coronavirus era are at world's doorstep, UN warns. New York Times 2020 Sep 5. https://www.nytimes.com/2020/09/05/ world/africa/coronavirus-famine-warning-.html 
21 New wave of famine could sweep the globe, overwhelming nations already weakened by years of conflict, warn UN officials. UN News 2020 Sep 18. https://news.un.org/en/story/2020/09/1072712

22 New report shows hunger is due to soar as coronavirus obliterates lives and livelihoods. World Food Programme, 2020. https://www.wfp.org/news/ new-report-shows-hunger-due-soar-coronavirusobliterates-lives-and-livelihoods

23 WFP global update on covid-19. World Food Programme, 2020. https://www.wfp.org/ publications/wfp-global-update-covid-19november- 2020

24 COVAX: ensuring global equitable access to COVID-19 vaccines. GAVI, the Vaccine Alliance, 2020. https://www.gavi.org/covid19/covax-facility

25 Mullard A. How COVID vaccines are being divvied up around the world. Nature 2020 Nov 30. doi:10.1038/d41586-020-03370-6

26 Hnizdo E, Murray J. Risk of pulmonary tuberculosis relative to silicosis and exposure to silica dust in South African gold miners. Occup Environ Med 1998:55:496-502. doi:10.1136/ oem.55.7.496

27 Stuckler D Steele S, Lurie M, Basu S. Introduction: 'dying for gold': the effects of mineral mining on HIV, tuberculosis, silicosis, and occupational diseases in southern Africa. Int J Health Serv 2013;43:639-49. doi:10.2190/HS.43.4.C

28 Oliver T. An address on occupational and other causes of pulmonary fibrosis: delivered to the North of England Branch of the British Medical Association, February 19th, 1925. Br Med J 1925;1:685-7. doi:10.1136/bmj.1.3354.685
29 Richardson B. Sugar: refined power in a global regime. Springer, 2009. doi:10.1057/9780230251007

30 Fool me twice. NCD Advocacy Report. Vital Strategies, 2019. https://www.vitalstrategies.org/wp-content/ uploads/2019/06/FoolMeTwice_Report.pdf

31 Collin J, Ralston R, Hill S, et al. Signalling virtue, promoting harm unhealthy commodity industries and COVID-19. NCD Alliance and SPECTRUM, 2020. https://ncdalliance.org/sites/default/files/resource_ files/Signalling\%20Virtue\%2C\%20Promoting\%20 Harm Sept2020 FINALv.pdf

32 Mazel 0 . Indigenous health and human rights: a reflection on law and culture. Int I Environ Res Public Health 2018;15:789. doi:10.3390/ijerph15040789

33 Commission on the Social Determinants of Health. Closing the gap in a generation: health equity through action on the social determinants of health. World Health Organization, 2008. https:// www.who.int/social_determinants/final_report/ csdh_finalreport_2008.pdf

34 Piketty T. Capital in the twenty-first century. Harvard University Press, 2014 doi:10.4159/9780674369542

35 Freudenberg N. Lethal but legal: corporations, consumption, and protecting public health. Oxford University Press, 2014.

36 Neate $\mathrm{R}$. Ten billionaires reap $\$ 400 \mathrm{bn}$ boost to wealth during pandemic. Guardian 2020 Dec 19. https://www.theguardian.com/technology/2020/ $\mathrm{dec} / 19 /$ ten-billionaires-reap-400bn-boost-towealth-during-pandemic

37 McMichael A. Climate change and the health of nations: famines, fevers, and the fate of populations. Oxford University Press, 2017. doi:10.1093/oso/9780190262952.001.0001

38 Mialon M, Vandevijvere S, Carriedo-Lutzenkirchen A, et al. Mechanisms for addressing and managing the influence of corporations on public health policy, research and practice: a scoping review. BMJ Open 2020;10:e034082. doi:10.1136/ bmjopen-2019-034082

39 Binding treaty on transnational corporations. Transnational Institute, 2020. https://www.tni.org/ en/topic/the-treaty-alliance

40 Wadvalla B-A. How Africa has tackled covid-19. BMJ 2020;370:m2830. PMID:32675053 doi:10.1136/ bmj.m2830

41 Anoko JN, Barry BR, Boiro H, et al. Community engagement for successful COVID-19 pandemic response: 10 lessons from Ebola outbreak responses in Africa. BMJ Glob Health 2020;4(Supp 7):e003121. doi:10.1136/bmjgh-2020-003121

42 Finnegan C. US declines to join global COVID-19 vaccine effort because of WHO's role. ABC News 3 September 2020. https://abcnews.go.com/Politics/us-declines-joinglobal-covid-19-vaccine-effort/story?id=72770704

43 Usher AD. South Africa and India push for COVID-19 patents ban. Lancet 2020;396:1790-1. doi:10.1016/S0140-6736(20)32581-2

44 MSF response to Gavi's intent to purchase SanofiGSK COVID-19 vaccine candidate for the COVAX Facility. Médecins Sans Frontières, 2020. https:// msfaccess.org/msf-response-gavis-intent-purchasesanofi-gsk-covid-19-vaccine-candidate-covax-facility

Cite this as: $B M / 2021 ; 372: \mathrm{n} 73$

http://dx.doi.org/10.1136/bmj.n73 